\title{
Development of a 2-Dimensional Model of Temperature Distribution in NST 37-2 Steel Quenched in Oil Using MATLAB.
}

\author{
Mudashiru, Lateef Owolabi \\ Department of Mechanical Engineering \\ Ladoke Akintola University of Technology \\ Ogbomoso, Nigeria \\ Corresponding Author's E-mail: oyeadeaga@tech-u.edu.ng \\ Adeaga, Oyetunde Adeoye \\ Department of Mechanical Engineering \\ The Ibarapa Polytechnic \\ Eruwa, Nigeria \\ Adegbola, Adeyinka Ayoade \\ Department of Mechanical Engineering \\ Ladoke Akintola University of Technology \\ Ogbomoso, Nigeria
}

\begin{abstract}
Quenching, being an important process for producing steel components with reliable mechanical properties and service requirement, is characterized with rejects, production hour losses, reworking and induced thermal stresses leading to cracking. This paper investigated thermal behaviour of cylindrical NST 37-2 steel during quenching process using oil as quenchant. A proposed model based on two dimensional energy and heat transfer equation was developed. The form of this equation is obtained using the formula for heat conduction in a steel rod (NST-37-2 steel) and the rate of heat transfer with respect to time and then solving partial differential equation using the finite element method and the numerical computation was done using MATLAB R2010a. A steel bar made of material having constant thermal conductivity was considered, letting the length be $\mathrm{I}$ and the breadth be $\mathrm{r}$, constant thermal conductivity $\mathrm{k}$ and $\mathrm{T}$ representing the various temperature ranges distributed throughout the cylindrical rod at various elemental nodes, some logical assumptions such as: the material being a cylindrical steel rod, hence justifying use of cylindrical coordinate system, all points in the steel rod are assumed to be isothermal just before quenching begins, variation of temperature at different points in the material after quenching, rate at which heat is lost to the quenchant (oil), the direction of heat flow is assumed to be both radial and linear, the surface area gridded into nodes both in the radial and directions (50 nodal points for this case). Results observed indicates that temperature drops rapidly in the early cooling period and as the cooling period progresses, the decrement in temperature attains almost steady state with advancing cooling time in NST 37-2 steel.
\end{abstract}

Keywords: - Quenchants, NST 37-2 steel, Finite Element Analysis (FEM), Cooling time, Matrix Laboratory (MATLAB).

Aims Research Journal Reference Format:

Mudashiru, L.O, Adeaga, O.A, Adegbola, A.A. (2018): Development of a 2-Dimensional Model of Temperature Distribution

in NST 37-2 Steel Quenched in Oil Using MATLAB. Advances in Multidisciplinary \& Scientific Research Journal. Vol. 4. No.2, Pp 55-64

\section{INTRODUCTION}

Steel production is one of the most important industries in the engineering field. However, for a steel company to succeed in tough competition, it is necessary to constantly optimize the production process itself. The optimization should lead not only to improvement in the quality of the final product, but also to increase productivity and reduce overall production costs. Heat transfer is increasingly important in various areas, namely in the earth sciences, and in many other evolving areas of thermal analysis. A common example of heat transfer is heating an object in an oven or furnace. The material remains stationary throughout, neglecting thermal expansion, as the heat diffuses inward to increase its temperature. The importance of such conditions leads to analyze the temperature field by employing sophisticated mathematical and advanced numerical tools.[1] 


\subsection{Quenching}

Quenching is a heat treatment usually employed in industrial processes in order to control mechanical properties of steels such as hardness. The process consists of raising the steel temperature above a certain critical value, holding it at that temperature for a specified time and then rapidly cooling it in a suitable medium to room temperature. The resulting microstructures formed from quenching (ferrite, cementite, pearlite, upper bainite, lower bainite and martensite) depend on cooling rate and on chemical composition of the steel. Quenching of steels is a multi-physics process involving a complicated pattern of couplings among heat transfer. Because of the complexity, coupled (thermal- mechanicalmetallurgical) theory and non-linear nature of the problem, no analytical solution exists. However, numerical solution is possible by finite difference method, finite volume method, and the most popular one - finite element method (FEM). During the quenching process of the steel bar, the heat transfer is in an unsteady state as there is a variation of temperature with time.[2]

\subsection{Finite Element Analysis}

The finite element method (FEM) is the dominant discretization technique in structural mechanics. The basic concept in the physical interpretation of the FEM is the subdivision of the mathematical model into disjoint (non-overlapping) components of simple geometry called finite elements or elements for short. The response of each element is expressed in terms of a finite number of degrees of freedom characterized as the value of an unknown function, or functions, at a set of nodal points. The response of the mathematical model is then considered to be approximated by that of the discrete model obtained by connecting or assembling the collection of all elements. The disconnection-assembly concept occurs naturally when examining many artificial and natural systems. For example, it is easy to visualize an engine, bridge, building, airplane, or skeleton as fabricated from simpler components. Unlike finite difference models, finite elements do not overlap in space.[3]

\section{METHODOLOGY}

The proposed model will be based on two dimensional energy and heat transfer equation. The form of this equation is obtained using the formula for heat conduction in a steel rod (NST-37-2 steel) and the rate of heat transfer with respect to time and then solving partial differential equation using the finite element method and the numerical computation will be done using MATLAB R2010a.

In order to derive material model for the rate of heat transfer in a steel rod, the following considerations will be made:

1. The material is a cylindrical steel rod, hence justifying use of cylindrical coordinate system.

2. All points in the steel rod are assumed to be isothermal just before quenching begins.

3. Variation of temperature at different points in the material after quenching.

4. Rate at which heat is lost to the quenchant (oil).

5. The direction of heat flow is assumed to be both radial and linear.

6. The surface area will be gridded into nodes both in the radial and $\theta$ directions (50 nodal points for this case).

Also to derive the material model for the rate of heat transfer in steel, the following assumptions will be made:

1. Two dimensional conditions. i.e bi-symmetrical transfer about the center lines of the rod.

2. The material is isotropic i.e exhibits same properties throughout.

3. No continuous internal heat generation.

4. Heat loss by conduction only in the radial and axial directions.

5. Heat loss by convection only along the circular ends and curved surfaces of the rod.

6. Direction of heat flow is linear.

7. Heat flows by conduction. 


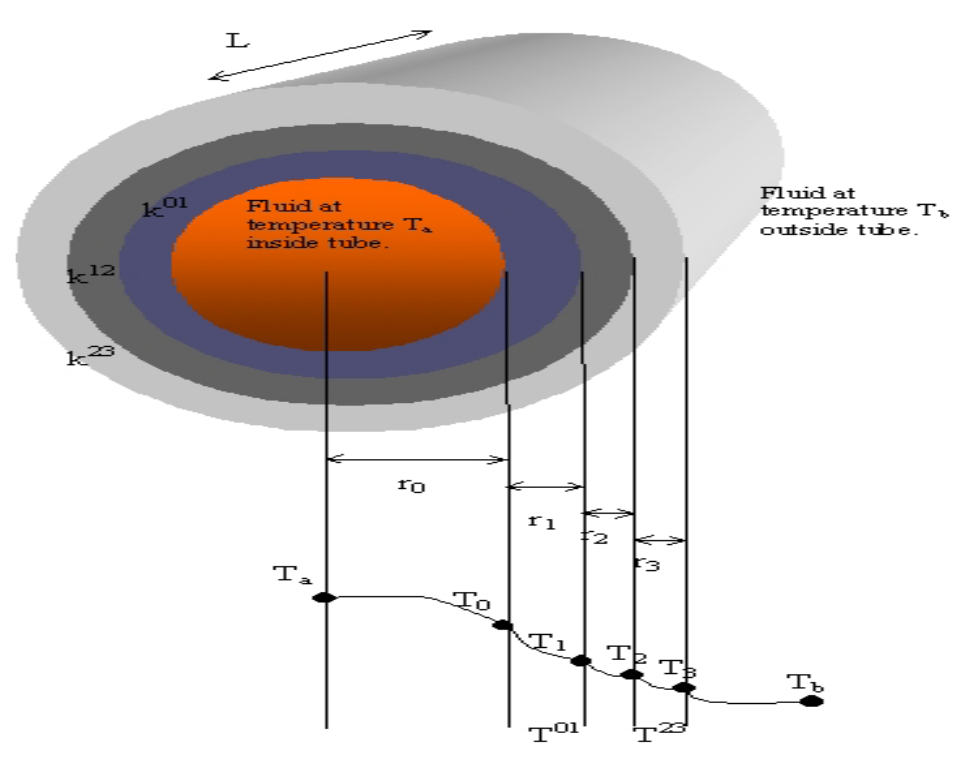

Figure 1: Physical model of the steel rod.

The rate at which heat is conducted across as a steel rod i.e cylindrical surface in the solid may be expressed as

$$
Q=-k \cdot A \frac{d T}{d x}=-k\left(\pi r^{2}\right) \frac{d T}{d x}
$$

Considering a steel bar made of material having constant thermal conductivity and let the length be $I$ and the breadth be $\boldsymbol{r}$, constantthermal conductivity $\boldsymbol{k}$ and $\mathbf{T}$ represents the various temperature ranges distributed throughout the cylindrical rod at various elemental nodes.

Based on the above assumptions the equation for the energy and heat transfer equations within the steel, the general equation for heat transfer in a steel rod is:

$$
\begin{aligned}
& Q_{r}+Q_{\theta}+Q_{z}-Q_{r+\Delta r}-Q_{\theta+\Delta \theta}-Q_{z+\Delta z}+E_{\text {gen }, \text { Element }}=\frac{\Delta E_{\text {slement }}}{\Delta t} 3.2 \\
& \frac{\Delta E_{\text {slemsnt }}}{\Delta T}=m C \frac{d T}{d t} 3.3 \\
& m=\rho V 3.4
\end{aligned}
$$

Also the heat generated is generally given as:

$$
\begin{aligned}
& Q_{r}=-k A_{r} \frac{d T}{d r} 3.5 \\
& Q_{\theta}=-k A_{\theta} \frac{d T}{d \theta} 3.6 \\
& Q_{g}=-k A_{g} \frac{d T}{d g} 3.7
\end{aligned}
$$

Equation 3.1 can be converted using Taylor series expansion to become:

$$
k\left(\frac{\partial^{\mathrm{n}} T}{\partial r^{2}}+\frac{1}{r} \frac{\partial T}{\partial r}+\frac{1}{r^{2}} \frac{\partial^{2} T}{\partial \theta^{2}}+\frac{\partial^{\mathrm{n}} T}{\partial z^{2}}\right)+E_{g e n, \theta l e m e n t}=\rho C \frac{d T}{d t} 3.8
$$


Upon assumption that there is no internal heat generation and a $2 \mathrm{D}$ model, then there will be no heat flow along the circumferential of the cylindrical steel rod, therefore $\frac{a^{2} T}{\partial \theta^{2}}=0$ and $E_{\text {gen }, \text { element }}=0$, equation 3.8 becomes:

$k\left(\frac{\partial^{2} T}{\partial r^{2}}+\frac{1}{r} \frac{\partial T}{\partial r}+\frac{\partial^{2} T}{\partial z^{2}}\right)=\rho C \frac{d T}{d t} 3.9$

Dividing through by $\boldsymbol{k}$ :

$\left(\frac{\partial^{2} T}{\partial r^{2}}+\frac{1}{r} \frac{\partial T}{\partial r}+\frac{\partial^{2} T}{\partial z^{2}}\right)=\frac{\rho C}{k} \frac{d T}{d t}=\frac{1}{\alpha} \frac{d T}{d t} 3.10$

Where $\alpha=\frac{k}{\rho c}$ called the thermal diffusivity of the element.

Initial and Boundary conditions

Initial condition is the initial temperature of the steel at time $(t)=0$ given as:

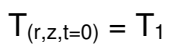

Also at time $\mathrm{t}=0$,

$\frac{\rho C}{k} \frac{d T}{d t}=\frac{1}{x} \frac{d T}{d t}=0$

Thus equation 3.10 becomes:

$$
\left(\frac{\partial^{2} T}{\partial r^{2}}+\frac{1}{r} \frac{\partial T}{\partial r}+\frac{\partial^{2} T}{\partial x^{2}}\right)=03.13
$$

The boundary conditions are given as:
At $\quad r=0, \frac{\partial T_{(0, z)}}{\partial r}=0$
$\mathrm{r}=\mathrm{R}, q=h A\left(T-T_{L}\right)=-k \frac{\partial T_{(R E=y H)}}{\partial r}$
At $\quad \mathrm{z}=0, \frac{\partial T}{\partial r}=0$
$\mathrm{z}=\mathrm{L}, \quad q_{z}=k A\left(T-T_{L}\right)=k \frac{\partial T_{(r, z=L, 0)}}{\partial z}$ 
Formula for the time rate.

In order to determine the time interval correspondence to the heat transfer rate; we use the approximate formula given below:

$d t=\frac{d x^{2}}{M a}$

Where $\mathrm{M}=$ module

$\alpha=$ thermal diffusivity

$$
d x=\frac{L}{N-1}
$$

Where $L=$ Edge length (i.e distance between two corresponding nodes)

$\mathrm{N}=$ Number of nodes.

Solving for the rate of heat transfer

Recall

$h=\frac{V \times p \times C_{P}}{A\left(T_{1}-T_{l}\right)} \times \frac{d T}{d t}$

Where $\mathrm{h}=$ heat transfer coefficient of the quenchant (water and oil)

$\mathrm{V}=$ volume of steel dipped in water

$\rho=$ density of steel metal

$\mathrm{C}_{\mathrm{p}}=$ Specific heat capacity

$A=$ Surface area

$\mathrm{T}_{1}=$ Initial temperature of steel

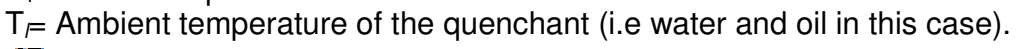

$\frac{d T}{d t}=$ rate of heat transfer with respect to time.

Equation 3.16 can be rearranged thus:

$$
\begin{aligned}
& d T=\frac{h \times A\left(T_{1}-T_{l}\right)}{V \times c_{p} \times p} \times d t \\
& T_{(i, j)}=T_{1}+d T
\end{aligned}
$$

Where $T_{(i, j)}$ is the temperature at different nodal points as time varies $\mathrm{dT}$ is the rate of heat loss to the quenchant.

$\mathrm{dt}$ is the time rate. 


\section{NUMERICAL SOLUTION}

Approximate technique of solution was used to solve the equation 3.9. The method in this study is the explicit finite element method and the equation was transformed into difference equation by dividing the domain of solution to a grid of points in the form of mesh and the derivatives were expressed along each mesh point referred to as a node. Knowing the dependent variable at each node initially and it is approximated for the next time step until the final step. The grid consists of two perpendicular lines representing the r-direction and z-direction.Using Taylor's series expansion in the $t$ (time) direction but keeping $r$ and $z$ (space) constant and truncate second term of the series, such that the equation for heat conduction can be discretized to become:

$$
\begin{aligned}
& \text { for } i=1_{i j} j=1_{i} \\
& T_{(i, j)}=\frac{T_{(i+1, j}+2 T_{z}+T_{(i, j+1}+(M-4) T_{(h, j)}}{M} \\
& \text { for } i=1_{j} j=N ; \\
& T_{(i, j)}=\frac{T_{(i+1, j}+2 T_{2}+T_{(i j-1)}+(M-4) T_{(i, j)}}{M} \\
& \text { for } i=N ; j=1 \\
& T_{(i, j)}=\frac{T_{(i-1, j}+2 T_{2}+T_{(i, j+1)}+(M-4) T_{(i, j)}}{M} \\
& \text { for } i=N_{;} j=N_{;} \\
& T_{(i, j)}=\frac{T_{(i-1, j}+2 T_{2}+T_{(i, j-1)}+(M-4) T_{(i, j)}}{M}
\end{aligned}
$$

\section{SIMULATION}

MATLAB was used as a simulation tool to implement solution and analysis of finite difference equation at different radial distance, axial distance and time rates for oil quenchers. Therefore, resulting equations from the finite difference technique was implemented in MATLAB by developing codes in its command window so as to predict the temperature distribution during the process using the following numerical parameters:

- Radius of steel $(\mathbf{r}): 20 \mathrm{~mm}=0.01 \mathrm{~m}$

- Length of steel in quenchant (L): $450 \mathrm{~mm}=0.045 \mathrm{~m}$

- Thermal conductivity (k): $64 \mathrm{~W} / \mathrm{mK}$

- $\quad$ Surface area $(\mathbf{A}): 3.142 \times 10^{-4} \mathrm{~m}^{2}$

- Part volume dipped in water $(\mathbf{V}): 1.414 \times 10^{-5} \mathrm{~m}^{3}$

- Heat transfer coefficient (h): $738 \mathrm{~W} / \mathrm{m}^{2} \mathrm{~K}$ for oil.

The value for heat transfer coefficient used for oil is determined from Canale (2000).

- $\quad$ Number of points $(\mathbf{N}): 50$

- Edge length (L): $0.4 \mathrm{~m}$

- Mass $(\mathbf{m})$ : approximately 113.8 grams $=0.1138 \mathrm{~kg}$ (as measured by a Digital weigh balance (scout pro product, capacity of $4000 \mathrm{~g})$

- Density $(\boldsymbol{\rho})=\frac{m}{v}=\frac{0.1138}{1.414 \times 10^{-5}}=8049.7 \mathrm{~kg} / \mathrm{m}^{3}$

- Specific heat capacity $\left(\mathbf{C}_{\mathrm{p}}\right)$ of steel: $700 \mathrm{j} / \mathrm{kg} \cdot \mathrm{K}$

- Initial temperature of NST $37-2\left(\mathbf{T}_{\mathbf{i}}\right): 850^{\circ} \mathrm{C}$

- Ambient temperature of quenchant $\left(\mathbf{T}_{\mathbf{1}}\right): 30^{\circ} \mathrm{C}$ for oil[4] 


\subsection{Simulated Results}

The temperature-time history (cooling curves) of steel at $850^{\circ} \mathrm{C}$, quenched in oil, having an ambient temperature of $30^{\circ} \mathrm{C}$ and monitored at different instances of time $(5,25,50$ seconds) is simulated.

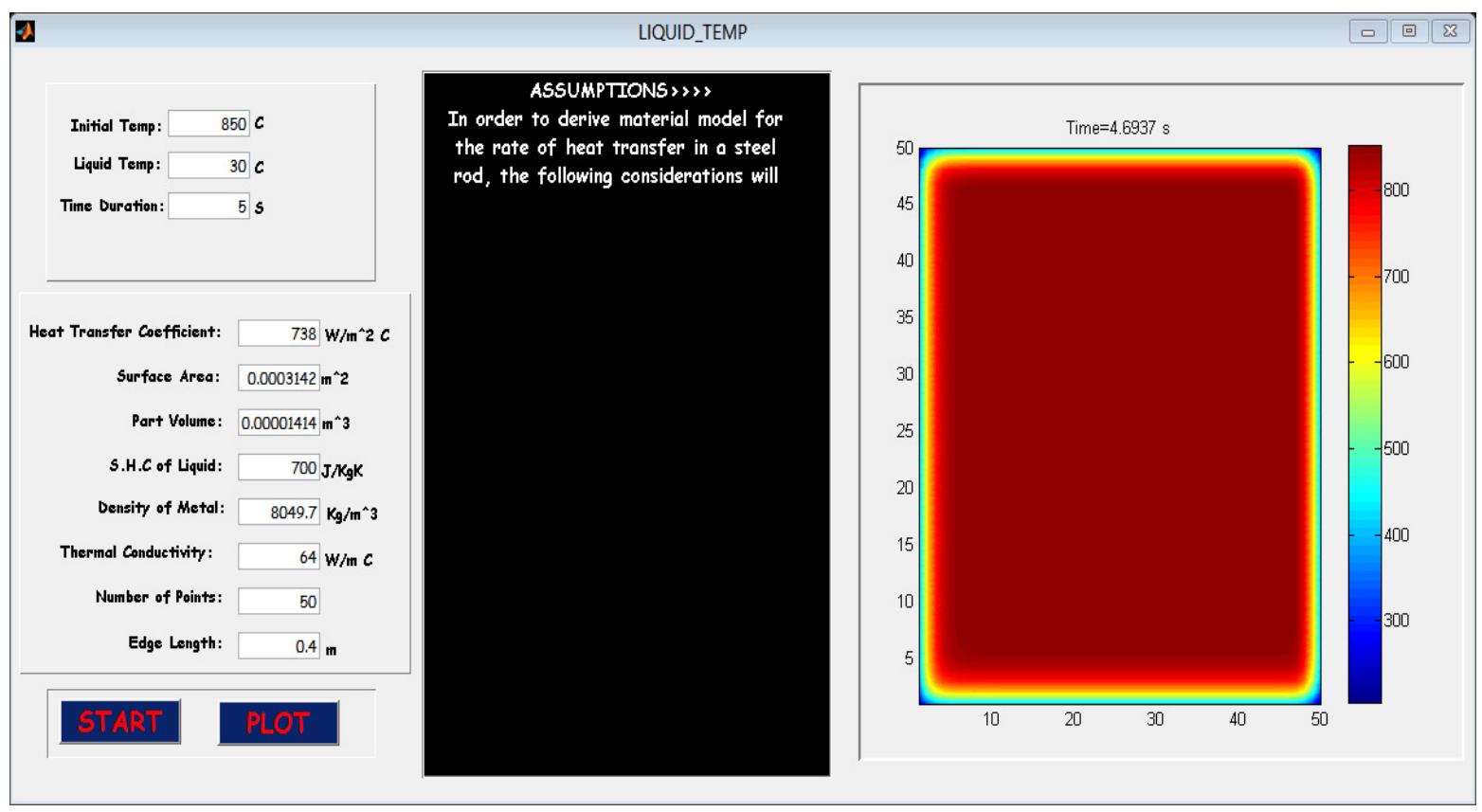

Figure 2a: Simulated model of the temperature profile of the steel after 5 seconds.

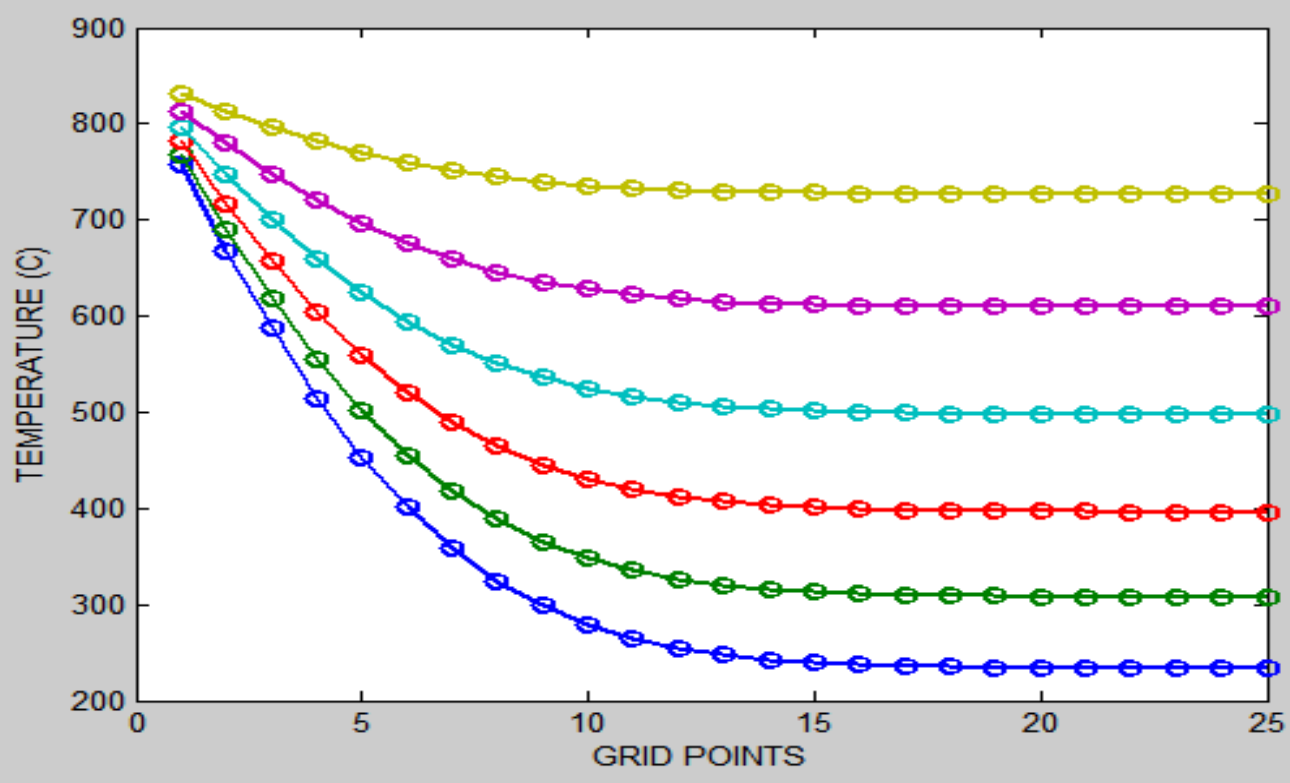

Figure 2b: Graph of temperature against the first 25 nodes after 5 seconds. 


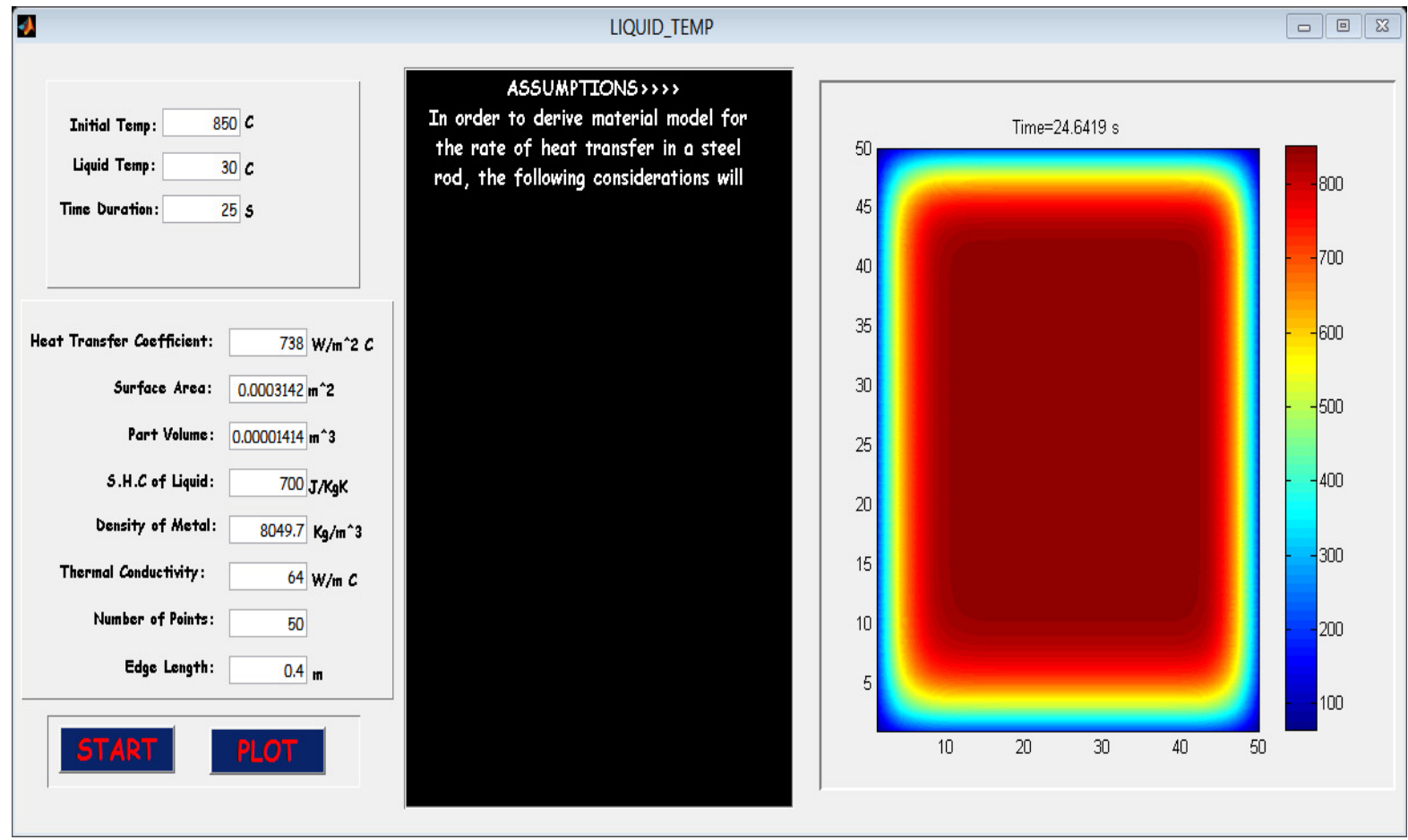

Figure 3a: Simulated model of the temperature profile of the steel after 25 seconds.

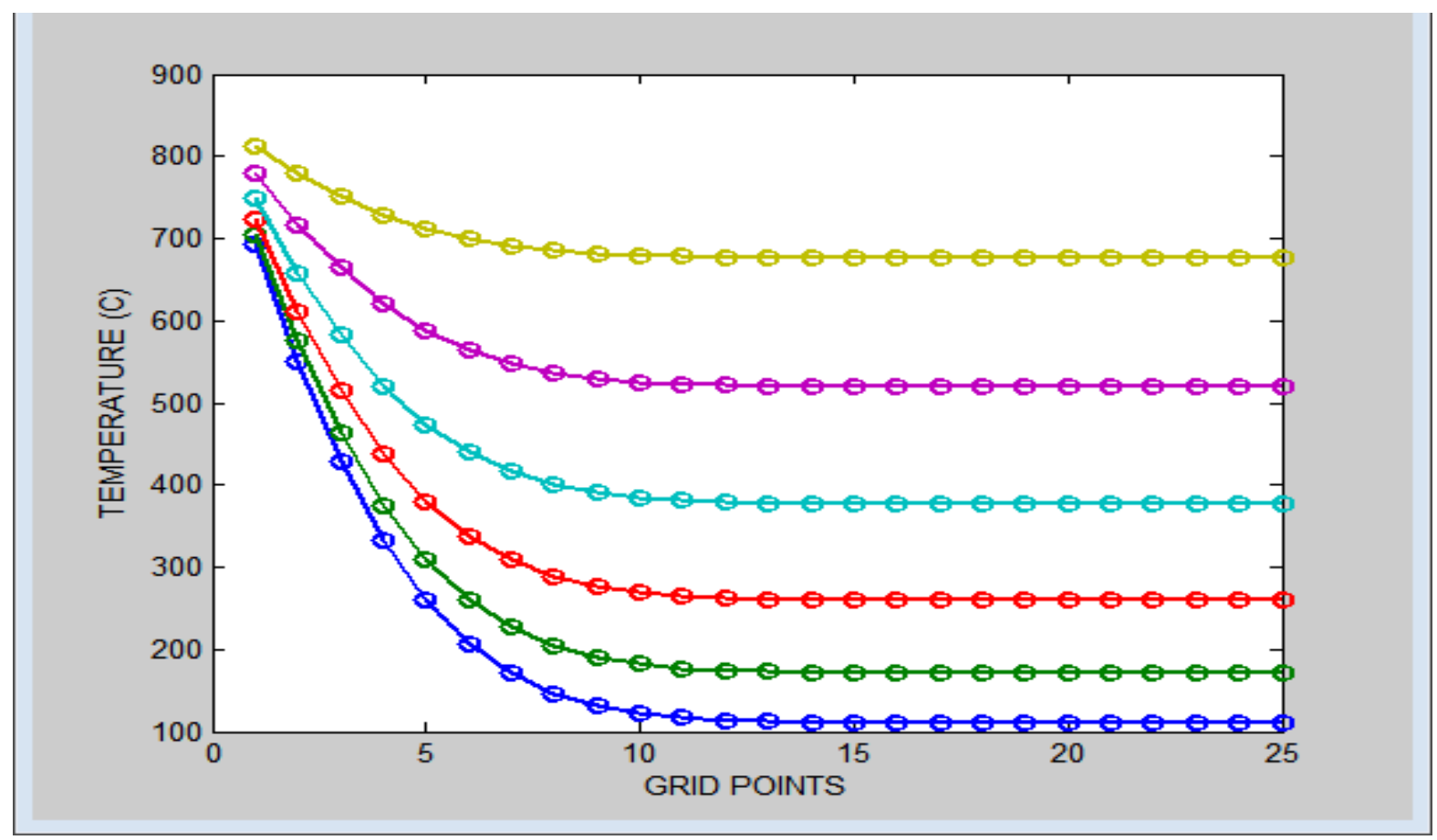

Figure 3b: Graph of temperature against the first 25 nodes after 25 seconds. 


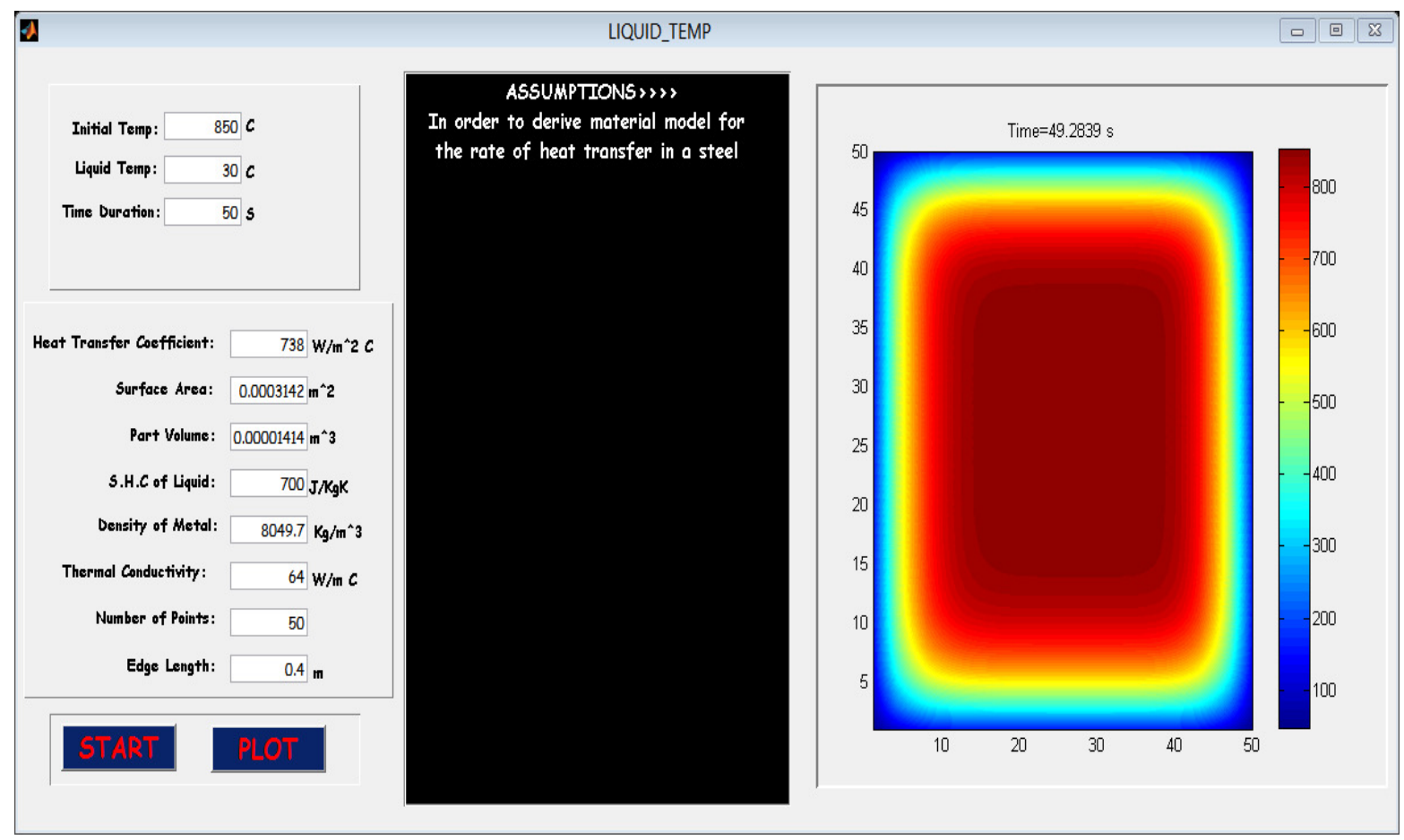

Figure 4a: Simulated model of the temperature profile of the steel after 50 seconds.

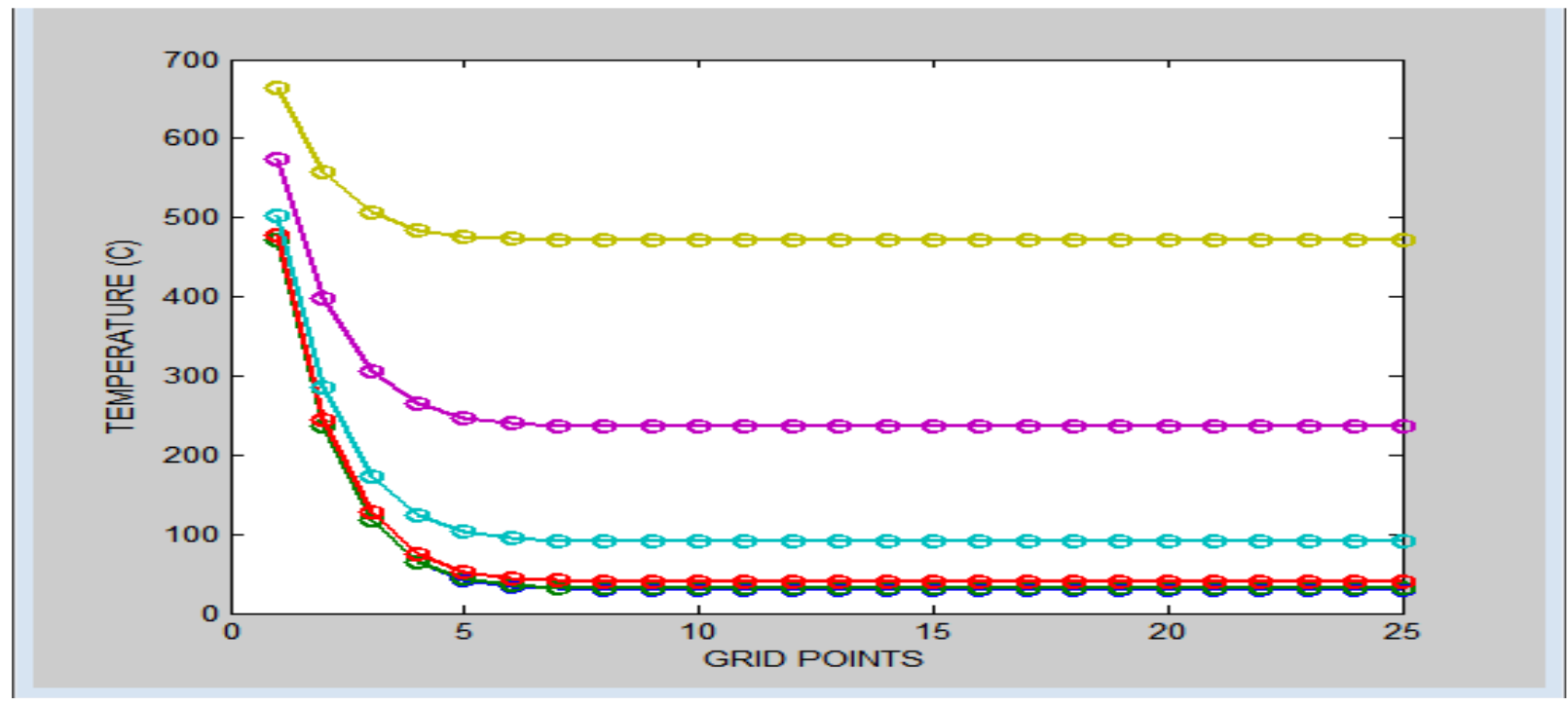

Figure 4b: Graph of temperature against the first 50 nodes after 25 seconds.

The data generated from the MATLAB model were plotted in form of graphs in the Figure 2 for the oil quenched steel at 5 second, Figures 3 for 25 seconds and Figure 4 for 50 seconds. The influence of time on the temperature distribution in the steel is observed in the set of figures plotted, each case sectioned into quadrants from the nodal points in order to make the results more presentable and easy to analyze. 


\section{CONCLUSION}

The model allows predictions of the rate of heat loss to the various quenchants, the temperature distribution and the thermal resistance. The model was solved using the modified numerical code in MATLAB R2010b.From this study it can be observed that temperature drops rapidly in the early cooling period and as the cooling period progresses, the decrement in temperature attains almost steady state with advancing cooling. Lastly, heat transfer model equation was solved for temperature distribution inside the steel due to convective boundary condition during quenching process. The obtained results show that with increase of time, temperature in the sample decreases and attains steady value with advancing time.

\section{References}

[1] Behera P, (2009). Analysis of Transient Heat Conduction In Different Geometries

[2] Elmaryami S.A. Badrul Omar (2013): Effect of Radius on Temperature History of Transient Industrial Quenched Chromium Steel-8650H by Developing 1-D MM. Applied Mathematical Sciences. 7(10): 471-486

[3] Barkanov E, (2001). Introduction To The finite Element Method.

[4] Engineering Toolbox (2015): Engine and Gear Oil - Temperature and Viscosity Limits available on www.engineeringtoolbox.com accessed on 29/4/2015 